\title{
Successful management of retropharyngeal hematoma by trans-arterial embolism without intubation
}

\author{
Gaku Sugiura ${ }^{1 *} \mathbb{D}$, Hiroyuki Takahashi ${ }^{1}$, Yoshihisa Kodama² and Satoshi Nara ${ }^{1}$
}

\begin{abstract}
Background: Retropharyngeal hematoma can cause suffocation if there is delay in securing the airway by intubation. However, there are also concerns about complications that can arise with intubation; it is still unknown which cases do not require intubation.

Case presentation: An 88-year-old woman slipped and was found prone and was transported to the emergency room. She was alert without any stridor. Physical examination revealed a subcutaneous hematoma in the anterior cervical region. Computed tomography revealed a retropharyngeal hematoma. Angiography and computed tomography angiography showed extravasation from the right costocervical trunk. A radiologist performed transarterial embolization, and she had an uneventful course without intubation or developing any complication. She became ambulatory on postoperative day 5 .

Conclusion: Angiography and computed tomography angiography help in early recognition of extravasation in retropharyngeal hematoma, and trans-arterial embolization can help to avoid intubation and its complications.
\end{abstract}

Keywords: Computed tomography angiography, Intubation, Hematoma, Embolization

\section{Background}

The retropharyngeal space is a broad anatomical space [1]. Between the posterior pharyngeal wall and the vertebral bodies, three potential spaces have been described one of which is the middle space. The middle space is a broad space and confluent with the posterior mediastinum. Considerable asymptomatic bleeding into the retropharyngeal space from venous, arterial, and fracture-associated sources can cause suffocation due to delayed hematoma formation. Bleeding may result from venous, arterial, and fractureassociated. To prevent this, early airway securing, such as through intubation and tracheostomy, has become more common [2, 3]. However, there are concerns about complications that may arise from intubation and tracheostomy,

\footnotetext{
* Correspondence: gakusugiura@gmail.com

${ }^{1}$ Emergency and Critical Care Medical Center, Teine Keijinkai Hospital, 1-jo

12-chome 1-40, Maeda, Teine-ku, Sapporo 006-8555, Japan

Full list of author information is available at the end of the article
}

such as ventilator-associated pneumonia (VAP), ventilatorinduced lung injury (VILI), and deep vein thrombosis (DVT) because of immobilization. It remains unknown which cases of retropharyngeal hematoma $(\mathrm{RPH})$ do not require intubation. There are some studies regarding trans-arterial embolization (TAE) as a management modality for RPH; however, there is no report that TAE prevents delayed hematoma development and suffocation. Here, we report our experience of avoiding intubation by $\mathrm{TAE}$, along with a literature review.

\section{Case presentation}

An 88-year-old woman slipped and was found prone in her house by her caregiver and transported to the emergency department by paramedics. She was down for $2 \mathrm{~h}$. Her medical history included thrombophlebitis, and she was taking $2.5 \mathrm{mg}$ warfarin daily. She was alert on presentation. Her vital signs were as follows: respiratory rate, 
24 breaths/min; peripheral capillary oxygen saturation was 98\% (in room air); blood pressure, $130 / 60 \mathrm{mmHg}$; heart rate, 80 b.p.m.; temperature, $36.6^{\circ} \mathrm{C}$. Head and neck examination revealed a subcutaneous hematoma in the anterior cervical region which was $40 \mathrm{~mm}$ in diameter, non-pulsatile, not expanding, and not crepitus. Lungs were clear and no stridor at presentation. Neurological, cardiovascular, and abdominal examination were unremarkable. Computed tomography (CT) revealed RPH. CT angiography (CTA) showed extravasation around the hematoma (Fig. 1). To establish hemostasis, an angiography was performed. She was not intubated because she was alert and her respiratory condition was stable. Laboratory analysis revealed that the prothrombin international normalized ratio (PT-INR) was 3.83. We administered $20 \mathrm{mg}$ vitamin $\mathrm{K}$ and $1000 \mathrm{IU} 4-$ factor prothrombin complex concentrate (PCC). It also revealed mild anemia and mild thrombocytopenia, but there were no other abnormalities. The radiologist placed 4-Frlong sheath in the right femoral artery as an access site, thereafter performed coil embolization (Target XL 360 (Fig. 2) without sedation. She was admitted to the intensive care unit (ICU) with the following vitals: respiratory rate, 17 breaths/min; peripheral capillary oxygen saturation was $99 \%$ (in room air); blood pressure, 124/63 mmHg; heart rate, 66 b.p.m.; temperature, $36.5^{\circ} \mathrm{C}$. She was alert. She had an uneventful course without undergoing intubation or developing any complications. On postoperative day 3 , she was able to sit in a wheelchair, and she became ambulatory on postoperative day 5 . She was downgraded from the ICU on day 12. There was no complication after leaving the ICU. It took time to adjust the referral, and she was transferred to another hospital for rehabilitation on postoperative day 25 . Her vitals at time of discharge were as follows: respiratory rate, 15 breaths/min; peripheral capillary oxygen saturation was $97 \%$ (in room air); blood pressure, 108/64 mmHg; heart rate, 66 b.p.m.; temperature, $36.0^{\circ} \mathrm{C}$. If dyspnea appeared, she was to refer to a radiologist without follow-up.

\section{Discussion}

$\mathrm{RPH}$ is generally associated with cervical spine injury [4]. The thyrocervical artery [4-7] and vertebral artery $[1,8]$ have been reported as sources of RPH. There are

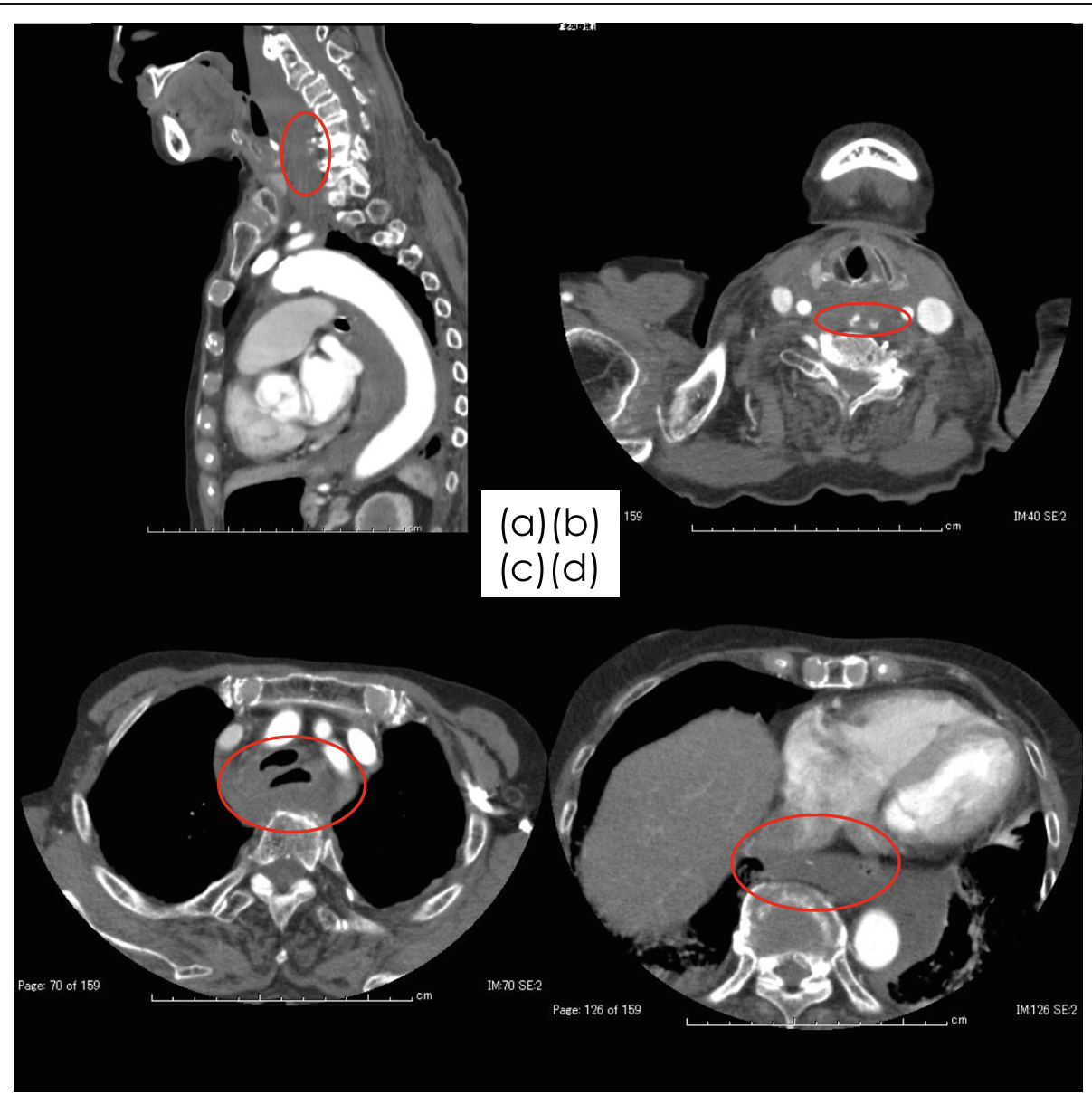

Fig. 1 Computed tomography scans show retropharyngeal hematoma and extravasation (circled area) (a, b). The hematoma extends to the posterior mediastinum and compresses the trachea $(\mathbf{c}, \mathbf{d})$ 


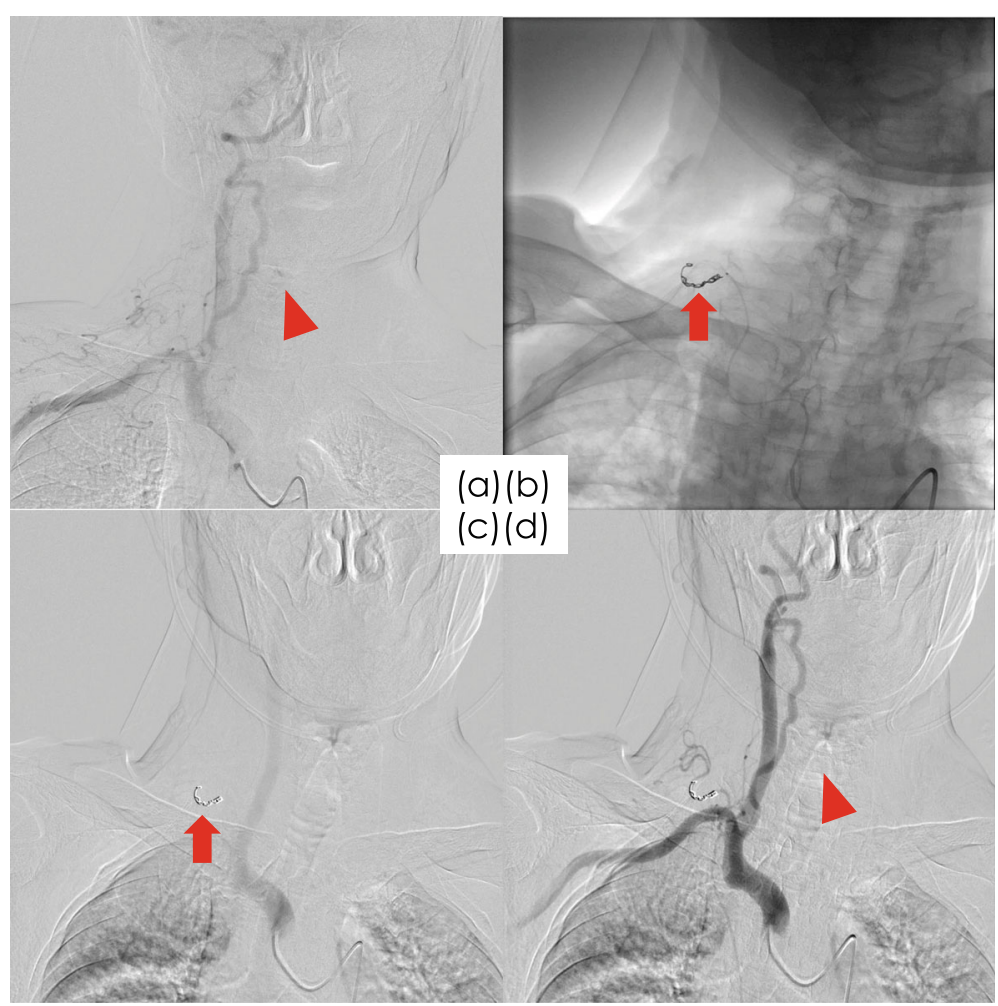

Fig. 2 Angiography images show a extravasation of contrast media (arrowhead) on the right costocervical artery, b, c performed TAE (arrow), and $\mathbf{d}$ the disappearance of the extravasation (arrowhead) after transcatheter arterial embolization

also RPH cases following stellar ganglion block [9] or anterior cervical fusion [10]. Van Velde et al. reported that flexion-extension trauma of the neck without fracture may lead to rupture of the small arteries [5]. This patient did not have cervical spine injury or recent surgery. We consider her mechanism to be similar to that of the previous report. RPH can be diagnosed with plain CT; however, there are limitations to diagnosing arterial bleeding. Therefore, when RPH is confirmed, we recommend CTA in addition. CTA makes it possible to evaluate blood vessels and decide whether to treat them with TAE or other methods, thus obviating intubation. While angiography can be used for evaluation, it carries a $1 \%$ risk of stroke when used to evaluate head and neck vessels. Therefore, angiography as a diagnostic procedure has been replaced in recent years by CTA [7].

On literature review, 6 cases were found in which AG was performed for RPH. The literature search was conducted on PubMed. The following keywords were used: "retropharyngeal hematoma" and "retropharyngeal hemorrhage." Of the 426 abstracts reviewed, 6 cases were selected in which AG was performed (Table 1). In 5 cases, TAE was performed. However, in all cases, TAE was performed after intubation. There have been no reports of avoiding intubation by TAE. In 2 cases, CTA was performed before AG.
In this case, selective angiography of the brachiocephalic artery revealed an extravasation in the neck. Bruch of the costocervical artery was considered as the source vessel, and coil was deployed. On literature review, coil and PVA were reported as a modality of embolization. In this case, the radiologist performed coil embolization concerning about cerebral infarction due to embolic substances.

There are also reports suggesting a conservative treatment of RPH with vitamin K and fresh frozen plasma in mild cases with no deterioration of respiratory status [11]. The patient in this case was taking warfarin. Laboratory analysis revealed that PT-INR was prolonged, and the patient was therefore administered vitamin $\mathrm{K}$ and a 4-factor PCC. It is important that improving the coagulation state also suppressed bleeding and helped avoid intubation.

Since the patient was alert with intact airway and breathing, she was observed without intubation. In previous reports about acute airway obstruction due to postoperative RPH after anterior cervical fusion, patients without fear, anxiety, and dyspnea could be stabilized with oxygen and close observation [10]. Such close observation is not only monitoring of the respiratory condition but also evaluation of consciousness. If the patient is excited or panicky even without dyspnea, this is a sign 
Table 1 Cases in which AG was performed for retropharyngeal hematoma

\begin{tabular}{|c|c|c|c|c|c|c|c|c|c|}
\hline $\mathrm{S} / \mathrm{N}$ & Age (years) & Sex & $\begin{array}{l}\text { Reason for } \\
\text { intubation }\end{array}$ & Airway management & Bleeding source & $\mathrm{CT}$ & TAE & Outcome & Source, Year \\
\hline 1 & 83 & M & Paradoxical breathing & $\begin{array}{l}\text { Endotracheal } \\
\text { intubation }\end{array}$ & Vertebral artery & CTA & y & Limb weakness & Kudo et al., 2017 [8] \\
\hline 2 & 80 & M & $\begin{array}{l}\text { Stridor, respiratory } \\
\text { distress }\end{array}$ & $\begin{array}{l}\text { Endotracheal } \\
\text { intubation }\end{array}$ & Thyrocervical artery & CECT & y & Not described & Calorego et al., 2015 [6] \\
\hline 3 & 65 & $\mathrm{~F}$ & Respiratory distress & $\begin{array}{l}\text { Nasopharyngeal } \\
\text { intubation }\end{array}$ & Thyrocervical artery & $\mathrm{CTA}$ & Coil & Not described & Jakanani et al., 2012 [7] \\
\hline 4 & 30 & $\mathrm{~F}$ & $\begin{array}{l}\text { Stridor, respiratory } \\
\text { distress }\end{array}$ & $\begin{array}{l}\text { Endotracheal } \\
\text { intubation }\end{array}$ & Thyrocervical artery & CECT & $n$ & $\begin{array}{l}\text { Transferred } \\
\text { (day 22) }\end{array}$ & lizuka et al., 2012 [4] \\
\hline 5 & 90 & M & Stridor & $\begin{array}{l}\text { Endotracheal } \\
\text { intubation }\end{array}$ & Left vertebral artery & CECT & PVA & $\begin{array}{l}\text { Extubated } \\
\text { (day 3) }\end{array}$ & Sheah et al., 2006 [1] \\
\hline 6 & 84 & $\mathrm{~F}$ & $\begin{array}{l}\text { Stridor, respiratory } \\
\text { distress }\end{array}$ & $\begin{array}{l}\text { Endotracheal } \\
\text { intubation }\end{array}$ & Thyrocervical artery & CECT & PVA & Uneventful & Van Velde et al., 2002 [5] \\
\hline 7 & 88 & $\mathrm{~F}$ & - & Observation & Costocervical artery & CTA & Coil & $\begin{array}{l}\text { Ambulatory } \\
\text { (day 5) }\end{array}$ & This case \\
\hline
\end{tabular}

AG angiography, CT computed tomography, CTA CT angiography, CECT contrast-enhanced CT, TAE trans-arterial embolization, $M$ male, $F$ female, $P V A$ polyvinyl alcohol

of airway obstruction. In this case, the patient was alert without dyspnea, tachypnea, and hypoxemia.

Secondly, by avoiding intubation, respiratory complications, such as VAP and VILI, could be avoided. In addition, intubation invariable immobilizes the patient increasing the risk of DVT. Such immobilization may be prolonged, as some reports indicate that resolution of hematoma needs 2 or 3 weeks, and long-term airway securing is needed $[2,12]$. The risk of complications thus increases with long-term airway securing; it is therefore important to perform intubation only in the most necessary cases. In this case, the patient became ambulatory on postoperative day 5 and complications were avoided. On literature review, there are no reports of becoming ambulatory immediately after intubation and AG (Table 1).

TAE is an effective strategy to control arterial hemorrhage, but it cannot control venous hemorrhage and fracture-associated hemorrhage. Therefore, the airway must be promptly secured in the case of venous or fracture-associated hemorrhage. In addition, even if TAE is performed, it is important to monitor the patient closely in the ICU and prepare for intubation if required. An enlarged hematoma can make intubation difficult, and the airway should be secured at the earliest sign of compromise.

\section{Conclusion}

Utilizing CTA in the evaluation of RPH ensures early recognition of extravasation while performing AG and TAE may help to avoid intubation and its possible complications.

Acknowledgements

Not applicable.
Authors' contributions

GS drafted the manuscript, analyzed and interpreted the data, and reviewed the literature. HT and YK conceived the idea for the study. SN critically reviewed the manuscript. All authors approved the final manuscript as submitted and agree to be accountable for all aspects of the work.

\section{Funding}

None.

Availability of data and materials

All data is included in the paper and table.

Ethics approval and consent to participate

Not applicable.

Consent for publication

The patient provided consent for publication.

Competing interests

The authors declare that they have no competing interests.

\section{Author details}

${ }^{1}$ Emergency and Critical Care Medical Center, Teine Keijinkai Hospital, 1-jo 12-chome 1-40, Maeda, Teine-ku, Sapporo 006-8555, Japan. ${ }^{2}$ Department of Radiology, Teine Keijinkai Hospital, Sapporo, Japan.

Received: 4 July 2020 Accepted: 21 November 2020

Published online: 07 January 2021

\section{References}

1. Sheah K, Hui F, Wansaicheong G, Khoo M. Retropharyngeal haemorrhage from a vertebral artery branch treated with distal flow arrest and particle embolisation. Singapore Med J. 2006;47:719-23.

2. Myssiorek D, Shalmi C. Traumatic retropharyngeal hematoma. Arch Otolaryngol Head Neck Surg. 1989;115:1130-2.

3. Mackenzie JW, Jellicoe JA. Acute upper airway obstruction. Spontaneous retropharyngeal haematoma in a patient with polycythaemia rubra vera. Anaesthesia. 1986;41:57-60.

4. lizuka S, Morita S, Otsuka H, et al. Sudden asphyxia caused by retropharyngeal hematoma after blunt thyrocervical artery injury. J Emerg Med. 2012:43:451-6.

5. Van Velde R, Sars PR, Olsman JG, Van De Hoeven H. Traumatic retropharyngeal haematoma treated by embolization of the thyrocervical trunk. Eur J Emerg Med. 2002;9:159-61. 
6. Calogero CG, Miller AC, Greenberg MR. Life-threatening retropharyngeal hemorrhage secondary to rupture of the inferior thyroid artery. Case Rep Emerg Med. 2015;2015:789076.

7. Jakanani G, Kenningham R, Bolia A. Active retropharyngeal hemorrhage from an acute thyrocervical artery injury: a rare complication of hyperextension cervical spine injury. J Emerg Med. 2012;43:e39-41.

8. Kudo S, Fukushima K, Hashimoto M, Furutake M, Tanaka K, Okada K. Airway and circulatory collapse due to retropharyngeal hematoma after blunt vertebral artery injury. Am J Emerg Med. 2017;35:806.e5-7.

9. Higa K, Hirata K, Hirota K, Nitahara K, Shono S. Retropharyngeal hematoma after stellate ganglion block: analysis of 27 patients reported in the literature. Anesthesiology. 2006;105:1238-45 discussion 5A-6A.

10. Song KJ, Choi BW, Lee DH, Lim DJ, Oh SY, Kim SS. Acute airway obstruction due to postoperative retropharyngeal hematoma after anterior cervical fusion: a retrospective analysis. J Orthop Surg Res. 2017:12:19.

11. Karmacharya P, Pathak R, Ghimire S, et al. Upper airway hematoma secondary to warfarin therapy: a systematic review of reported cases. N Am J Med Sci. 2015;7:494-502.

12. Betten DP, Jaquint JL. Traumatic retropharyngeal hematoma in a patient taking clopidogrel. Case Rep Emerg Med. 2018;2018:6147473.

\section{Publisher's Note}

Springer Nature remains neutral with regard to jurisdictional claims in published maps and institutional affiliations.

Ready to submit your research? Choose BMC and benefit from:

- fast, convenient online submission

- thorough peer review by experienced researchers in your field

- rapid publication on acceptance

- support for research data, including large and complex data types

- gold Open Access which fosters wider collaboration and increased citations

- maximum visibility for your research: over $100 \mathrm{M}$ website views per year

At BMC, research is always in progress.

Learn more biomedcentral.com/submissions 